\title{
Gerakan Ketahanan Pangan melalui Budidaya Ikan dalam Ember dalam Menghadapi Pandemik Covid-19 di Desa Kareo, Kabupaten Serang
}

\author{
Muh. Herjayanto ${ }^{1}$, Aris Munandar ${ }^{1}$, Ginanjar Pratama $^{1}$, Mas Bayu Syamsunarno ${ }^{1}$, \\ Rini Yanuarti ${ }^{2}$, Aidil Fadli Ilhamdy ${ }^{3}$, Itok Dwi Kurniawan ${ }^{4}$ \\ ${ }^{1}$ Jurusan Perikanan, Fakultas Pertanian, Universitas Sultan Ageng Tirtayasa \\ ${ }^{2}$ Jurusan Farmasi, Fakultas Sains dan Teknologi, Institut Sains dan Teknologi Al-Kamal \\ ${ }^{3}$ Program Studi Teknologi Hasil Perikanan, Universitas Maritim Raja Ali Haji \\ ${ }^{3}$ Prodi Ilmu Hukum, Fakultas Hukum, Universitas Sebelas Maret \\ *Corresponding author: ginanjarpratama@untirta.ac.id
}

\begin{abstract}
ABSTRAK
Desa Kareo merupakan salah satu desa yang terletak di Kecamatan Jawilan,. Kabupaten Serang, Banten. Mayoritas penduduk Desa Kareo merupakan pedagang, petani tradisional dan buruh harian lepas. Covid-19 menyebabkan dampak yang signifikan pada sektor perekonomian dan ketahanan pangan. Hal itu terlihat dari banyaknya para pekerja yang terkena pemutusan hubungan kerja. Salah satu solusi untuk menghadapi pandemik Covid-19 dalam sektor ketahanan pangan adalah kegiatan budidaya ikan dalam ember. Kegiatan ini diharapkan mampu mengatasi permasalahan yang dihadapi selama pandemi. Kegiatan ini bertujuan untuk mengedukasi masyarakat tentang cara membudidayakan ikan dalam ember sebagai gerakan ketahanan pangan keluarga. Pengabdian ini dilakukan dengan beberapa tahapan yaitu tahap persiapan (koordinasi dengan Ketua RT), penyuluhan (survei dan evaluasi pengetahuan masyarakat tentang budikdamber), pelatihan budidaya, aplikasi/praktik langsung yang dilakukan oleh masyarakat, dan yang terakhir adalah monitoring-evaluasi. Hasil yang diperoleh dari kegiatan ini adalah meningkatnya pemahaman masyarakat tentang cara budidaya ikan dalam ember. Selain itu, sebanyak $80 \%$ warga yang memelihara ikan berhasil dalam mengaplikasikan kegiatan budidaya dalam ember ini.
\end{abstract}

Kata kunci: ketahanan pangan, budikdamber, Covid-19

\section{ABSTRACT}

Kareo Village is one of the villages located in the Jawilan District. Serang Regency, Banten. The majority of the residents of Kareo Village are traders, traditional farmers, and casual daily laborers. Covid-19 has had a significant impact on the economic and food security sectors. This can be seen from the number of workers who have been terminated. One solution to dealing with the Covid-19 pandemic in the food security was fish farming activities in buckets. This activity was expected to be able to overcome the problems faced during the pandemic. The objective of this activity was to educate the public to know how to cultivate fish in buckets as a movement for family food security. The stages of this activity are the preparation stage (coordination with the Head of the RT), counseling (survey and evaluation of community knowledge about budikdamber), cultivation training, direct application/practice carried out by the community, and the last is monitoring-evaluation. The results obtained from this activity were an increase in the community's understanding of how to cultivate fish in buckets. In addition, as many as $80 \%$ of the residents who maintain are successful in applying the cultivation activities in this bucket.

Keywords: food security, cultivate fish in buckets, Covid-19

\section{PENDAHULUAN}

Desa Kareo merupakan salah satu desa yang terletak dekat dengan kawasan industri di
Kecamatan Jawilan, Kabupaten Serang. Luas wilayah Desa Kareo yaitu $3,42 \mathrm{~km}^{2}$ dengan jumlah penduduk 6.103 jiwa (BPS, 2019). Mayoritas pekerjaan penduduk di Desa Kareo, 
Kecamatan Jawilan adalah pedagang, petani tradisional dan buruh harian lepas. Petani di daerah ini hanya mengandalkan sawah tadah hujan tanpa adanya irigasi permanen (Purnama, 2019). Semenjak adanya wabah Covid-19 ,terdapat dampak yang sangat signifikan terhadap kehidupan masyarakat di pedesaan (Sarip et al., 2020). Adapun dampak yang terjadi pada masa pandemi Covid-19 ini adalah perekonomian masyarakat yang menurun, kerawanan pangan, harga beberapa kebutuhan meningkat, aktivitas sosial dibatasi sehingga kurang produktif, dan banyaknya pemutusan hubungan kerja (Rohmah, 2020).

Kondisi akibat wabah pandemi Covid-19 mengharuskan masyarakat menerapkan pola hidup sehat yang ketat sebagai upaya pencegahan. Pembangunan kesehatan pada hakikatnya bertujuan agar dapat meningkatkan kesadaran dan kemampuan hidup sehat bagi setiap orang. Hal ini didasarkan pada Gerakan Masyarakat Hidup Sehat (GERMAS) yang dicanangkan pemerintah melalui Inpres Nomor 1 tahun 2017 sebagai tindak lanjut program Indonesia sehat melalui pendekatan keluarga (Suryani et al., 2018). Penyediaan pangan sehat dan percepatan perbaikan gizi merupakan kegiatan GERMAS yang dapat dijadikan sebagai upaya pencegahan Covid-19 melalui pendekatan keluarga. Kegiatan tersebut juga dilakukan untuk mewujudkan pembangunan ketahanan pangan mulai dari tingkat keluarga.

Pembangunan ketahanan pangan diselenggarakan untuk memenuhi kebutuhan dasar manusia secara adil dan merata (Kurniawansyah et al., 2020). Menurut Purwaningsih (2008), konsep ketahanan pangan dapat diterapkan ke dalam 4 aspek yaitu ketersediaan pangan, keamanan pangan, kemerataan pangan dan keterjangkauan pangan. Upaya pembangunan ketahanan pangan dapat dilakukan melalui pemberdayaan manusia agar mampu mengelola dan memanfaatkan sumberdaya alam secara efisien dan berkelanjutan. Pada masa pandemi perwujudan ketahanan pangan yang paling mudah adalah memanfaatkan pekarangan menjadi lahan produktif. Salah satunya adalah menerapkan sistem budidaya berbasis akuaponik yang dapat meningkatkan gizi masyarakat (Perwitasari et al., 2019). Pengembangan sistem akuaponik yang murah, mudah dan dapat diaplikasikan adalah BUDIKDAMBER (budidaya ikan dalam ember) (Syamsunarno et al., 2020). Sistem tersebut hanya mengandalkan luasan lahan yang sedikit dan mampu memenuhi kebutuhan gizi masyarakat secara langsung (Saputri \& Rachmawatie, 2020).

Berdasarkan hal tersebut, pengembangan area pekarangan rumah menjadi lahan untuk budidaya di Desa Kareo, Kecamatan Jawilan, Kabupaten Serang menjadi solusi nyata dalam menghadapi pandemi Covid-19. Sistem ini dapat bermanfaat menunjang ketahanan pangan dalam aspek sosial, ekologi dan ekonomi bagi penduduk desa secara berkelanjutan (Sugiarso et al., 2017). Nilai ekonomi dari produk pekarangan dapat menunjang ketahanan pangan rumah tangga, dengan asumsi uang yang diperoleh dari penjualan produk digunakan untuk membeli kebutuhan pangan atau dikonsumsi sendiri, sehingga diharapkan dapat meningkatkan perekonomian dan mencukupi sumber pangan. Hal tersebut dapat menciptakan kemandirian pangan pada masyarakat dalam masa pandemi. Kegiatan ini bertujuan untuk mengedukasi masyarakat tentang cara membudidayakan ikan dalam ember sebagai gerakan ketahanan pangan keluarga.

\section{METODE}

Kegiatan ini dilakukan dengan beberapa tahapan meliputi persiapan, penyuluhan, pelatihan, penerapan dan evaluasi berkelanjutan (Riyanto et al., 2020).

\section{Tahap Persiapan}

Tahap persiapan dilakukan dengan cara berkoordinasi dengan Ketua RT 11 dan RT 12 di Desa Kareo, Kecamatan Jawilan, Kabupaten Serang. Pada tahap ini dilakukan perencanaan kegiatan bersama mitra. Perencanaan tersebut disusun bersama dengan mitra untuk kegiatan yang akan dilakukan kedepannya.

\section{Tahap Penyuluhan}

Tahap penyuluhan dibagi menjadi dua yaitu tentang budidaya ikan dalam ember dan pengolahan serta pengemasan hasil dari budidaya. Pada tahap kedua dilakukan survei pengetahuan masyarakat tentang budidaya ikan, sistem budidaya ikan dalam ember, kandungan gizi ikan dan tanaman yang dibudidayakan, serta jenis kemasan produk. Tahap ini dilakukan untuk mengumpulkan data tentang pengetahuan responden terhadap kegiatan budidaya ikan dalam ember dan produknya. 


\section{Tahap Pelatihan}

Tahap pelatihan dilakukan dengan cara menerapkan hasil penyuluhan secara langsung kepada masyarakat. Pada tahap ini masyarakat melakukan praktek dari tahap persiapan ember, penyusunan substrat tanaman menggunakan arang sekam, penebaran benih kangkung, aklimatisasi ikan lele dan cara pemberian pakan yang baik.

\section{Tahap Aplikasi}

Tahap aplikasi dilakukan oleh masyarakat dengan cara memuasakan ikan selama 2 hari, kemudian dilakukan pemberian pakan sesuai dengan bobot ikan selama pagi dan sore hari. Tahap selanjutnya adalah menguras air, jika warna dan bau air sudah berubah serta melaporkan jumlah kematian ikan.

\section{Tahap Evaluasi}

Tahap evaluasi dilakukan oleh tim pengabdian dengan cara memonitor kualitas air, pemberian pakan ikan, kesehatan ikan dan tanaman, serta penyediaan pakan lanjutan sesuai dengan bobot ikan selama 2 minggu.

\section{HASIL DAN PEMBAHASAN}

Tahap persiapan awal yang dilakukan adalah menemui Ketua RT 11 dan 12 Desa Kareo (Gambar 1). Pada tahap ini dilakukan sosialisasi tentang gambaran pelaksanaan kegiatan pengabdian masyarakat budidaya ikan dalam ember. Pemaparan kebutuhan dan tahapan kegiatan dilakukan pada tahap persiapan ini. Hasil koordinasi awal didapatkan bahwa untuk pelaksanaan penyuluhan dan pelatihan dilakukan di Mushola Kp. Kareo Pasir Julang sedangkan untuk tahapan aplikasi atau penerapan kegiatan dilakukan di rumah warga sesuai dengan arahan dari Ketua RT masingmasing.

Pada tahap kedua dilakukan penyuluhan tentang budidaya ikan dalam ember dan pengolahan serta pengemasan produk hasil budidaya. Kegiatan ini diawali dengan survei pengetahuan masyarakat tentang sistem budidaya ikan dalam ember. Survei dilakukan kepada 30 orang responden dengan beberapa pertanyaan mengenai materi dari penyuluhan (Pratama et al., 2020). Pada survei ini diberikan pertanyaan mengenai budidaya ikan sistem akuaponik, istilah budikdamber, kandungan gizi ikan, kandungan gizi kangkung dan kemasan yang baik. Berdasarkan survei awal didapatkan bahwa 5 responden mengetahui/berpengalaman dalam membudidayakan ikan, tetapi seluruh responden tidak mengetahui istilah budikdamber. Untuk pertanyaan mengenai kandungan gizi ikan dan kangkung serta kemasan yang baik hanya 2 orang yang mengetahui (Tabel 1).

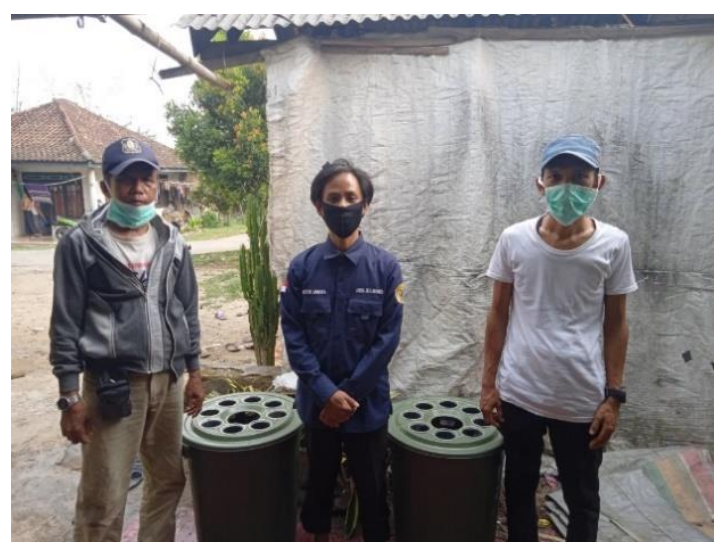

Gambar 1. Koordinasi dengan Ketua RT 11 dan 12 Desa Kareo

Kegiatan selanjutnya adalah penyuluhan mengenai budidaya ikan dalam ember yang menerangkan tentang tata cara budidaya ikan dalam ember yang baik (Gambar 2). Menurut Susetya \& Harahap, (2018) budidaya ikan dalam ember merupakan konsep budidaya yang diadaptasi dari teknik Yumina-Bumina. Teknik ini merupakan teknik budidaya yang memadukan antara ikan dan sayuran serta buahbuahan. Sistem Yumina-Bumina diketahui memiliki empat kategori, yaitu: rakit, aliran atas, aliran bawah serta pasang surut. Pada sistem aliran atas ini distribusi air dilakukan lewat atas ke setiap wadah media tanam sehingga nutrisi yang berasal dari limbah budidaya dapat tersebar merata ke setiap batang tanaman. Materi yang diberikan mencakup kualitas air, pemberian pakan, serta perhitungan nutrisi bagi ikan dan tanaman. Penyuluhan selanjutnya adalah mengenai cara pengolahan dan pengemasan hasil budidaya ikan dalam ember. Materi yang diberikan diawali tentang kandungan gizi ikan lele dan kangkung, kemudian cara mengolahnya dan yang terakhir adalah jenis-jenis kemasan yang baik digunakan. Pada materi ini masyarakat sangat antusias tentang mitos kangkung yang dapat menyebabkan kantuk. Menurut Astuti \& Fitriyanti (2018) kangkung memiliki efek sedasi-hipnotik akibat adanya kandungan kalium dan kuersetin (flavonoid). Kandungan ini mempunyai efek menenangkan sehingga dapat menyebabkan rasa ingin beristirahat. 
Tabel 1. Survei pengetahuan masyarakat tentang budidaya ikan dalam ember

\begin{tabular}{clcc}
\hline No & \multicolumn{1}{c}{ Pertanyaan } & $\begin{array}{c}\text { Mengetahui } \\
\text { (Jumlah } \\
\text { orang) }\end{array}$ & $\begin{array}{c}\text { Kurang } \\
\text { Paham } \\
\text { (Jumlah } \\
\text { orang) }\end{array}$ \\
\hline 1 & Apakah Bapak/Ibu mengetahui cara budidaya ikan? & 5 & 25 \\
2 & Apakah Bapak/Ibu mengetahui istilah budikdamber? & 0 & 30 \\
3 & Apakah Bapak/Ibu mengetahui kandungan gizi dari ikan lele? & 2 & 28 \\
4 & Apakah Bapak/Ibu mengetahui kandungan gizi dari kangkung? & 2 & 28 \\
5 & Apakah Bapak/Ibu mengetahui kemasan yang baik? & 2 & 28 \\
\hline
\end{tabular}

Tabel 2. Hasil evaluasi pengetahuan masyarakat tentang budidaya ikan dalam ember

\begin{tabular}{llcc}
\hline No & \multicolumn{1}{c}{ Pertanyaan } & $\begin{array}{c}\text { Mengetahui } \\
\text { (Jumlah } \\
\text { orang) }\end{array}$ & $\begin{array}{c}\text { Kurang } \\
\text { Paham } \\
\text { (Jumlah } \\
\text { orang) }\end{array}$ \\
\hline 1 & Apakah Bapak/Ibu mengetahui cara budidaya ikan? & 30 & 0 \\
2 & Apakah Bapak/Ibu mengetahui istilah budikdamber? & 30 & 0 \\
3 & Apakah Bapak/Ibu mengetahui kandungan gizi dari ikan lele? & 30 & 0 \\
4 & Apakah Bapak/Ibu mengetahui kandungan gizi dari kangkung? & 30 & 0 \\
5 & Apakah Bapak/Ibu mengetahui kemasan yang baik? & 30 & 0 \\
\hline
\end{tabular}

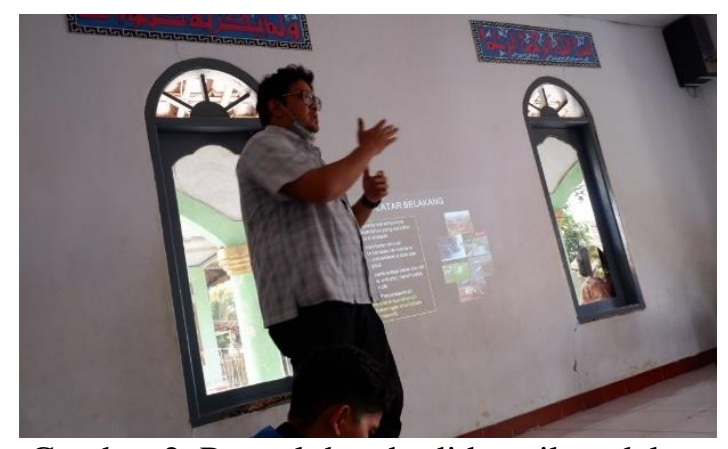

Gambar 2. Penyuluhan budidaya ikan dalam ember

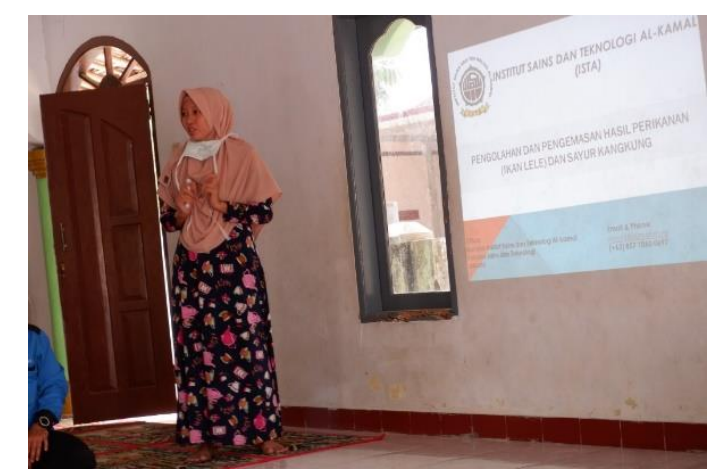

Gambar 3. Penyuluhan pengolahan dan pengemasan hasil budidaya ikan dalam ember

Hasil dari penyuluhan di dapatkan bahwa seluruh masyarakat mengerti apa yang telah disampaikan oleh penyuluh. Hal itu terlihat dari hasil evaluasi masyarakat tentang beberapa pertanyaan yang telah diajukan sebelumnya (Tabel 2). Tahap selanjutnya adalah kegiatan pelatihan yang dilakukan sesuai dengan materi penyuluhan. Tahap ini dilakukan dengan cara memberikan standar pemberian arang sekam dan benih kangkung untuk satu cup. Arang sekam yang diberikan sebanyak kurang lebih $40 \%$ dari wadah cup dengan benih kangkung berjumlah 25-30 benih (Gambar 4). Kegiatan selanjutnya adalah aklimatisasi ikan lele dan penebaran bibit ikan sebanyak 70 ekor setiap ember (Gambar 5). Aklimatisasi dilakukan agar ikan dapat beradaptasi terhadap lingkungan (air) yang baru, sehingga ikan tidak stres (Nazlia \& Zulfiadi, 2018).

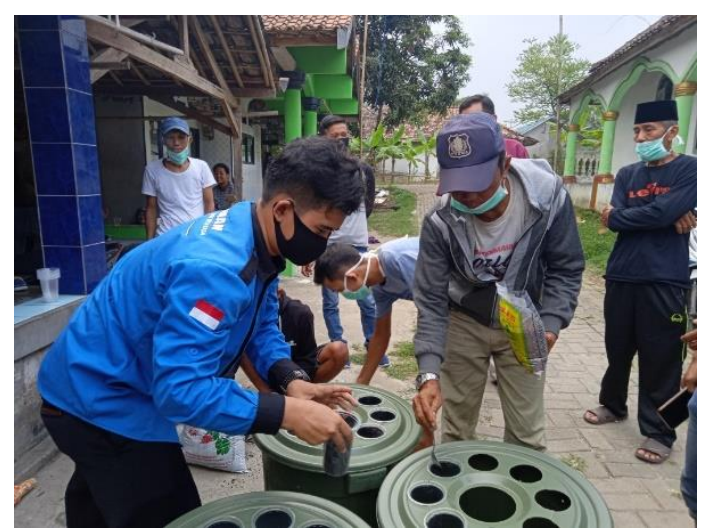

Gambar 4. Proses pemberian benih kangkung pada cup 


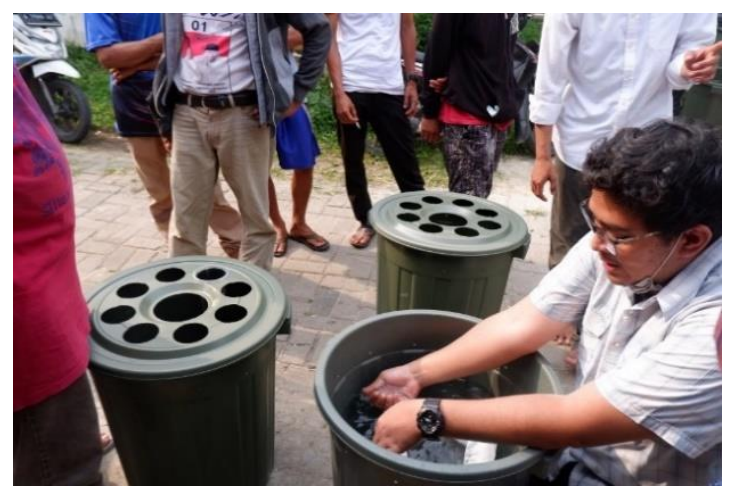

Gambar 5. Proses aklimatisasi ikan lele

Tahap selanjutnya adalah kegiatan aplikasi dan evaluasi. Pada tahap aplikasi masyarakat diberikan sepuluh set alat budikdamber yang ditempatkan di sepuluh rumah warga sesuai dengan petunjuk dari Ketua RT 11 dan 12. Pada tahap ini dimaksudkan untuk mengukur sejauh mana pemahaman masyarakat terhadap kegiatan budidaya ikan dalam ember secara langsung. Hasil evaluasi yang didapatkan selama dua minggu didapatkan bahwa ada dua ember yang mati secara massal akibat pemberian pakan yang tidak sesuai dengan takaran sehingga kualitas airnya menjadi kurang baik, sedangkan untuk delapan ember sisanya masih dalam tahap normal (Tabel 3). Hasil tersebut membuat para warga menjadi antusias karena $80 \%$ warga pemelihara telah berhasil mempelajari cara budidaya ikan dalam ember dengan baik. Antusias warga disekitar yang ingin memelihara pun semakin tinggi, mereka berlomba-lomba memodifikasi ember untuk memelihara ikan dan tanaman sebagai gerakan masyarakat dalam mendukung ketahanan pangan pada masa pandemi Covid19. Tahap pemeliharaan pada delapan ember selanjutnya dilakukan oleh warga hingga panen. Monitoring dilakukan menggunakan alat komunikasi jarak jauh hingga panen.

Tabel 3. Data pemeliharaan ikan lele oleh warga selama 2 minggu

\begin{tabular}{llcc}
\hline No. & Nama warga pemelihara & Mortalitas ikan lele $(\%)$ & Kondisi kangkung \\
\hline 1 & Sapa'at & 100 & Mati \\
2 & Rudi & 100 & Mati \\
3 & Sujito & 5,7 & Normal \\
4 & Manap & 1,4 & Normal \\
5 & Jimmy & 7,1 & Normal \\
6 & Kabir & 28,5 & Normal \\
7 & Ahmad Fajri & 14,2 & Normal \\
8 & Apendi & 2,8 & Normal \\
9 & Solehudin & 8,5 & Normal \\
10 & Mursani & 28,5 & Normal \\
\hline
\end{tabular}

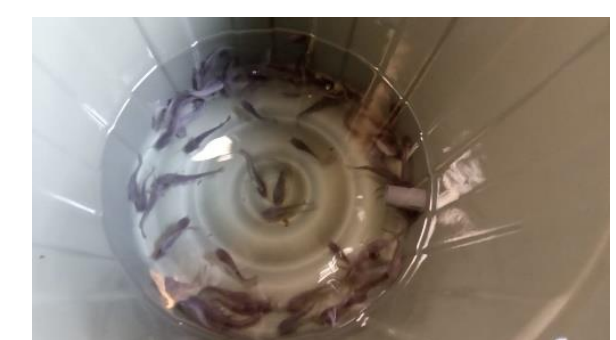

Gambar 6. Lele hasil pemeliharaan warga selama 2 minggu

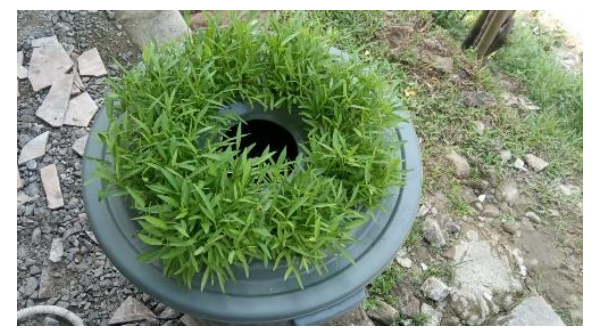

Gambar 7. Kangkung hasil pemeliharaan warga selama 2 minggu

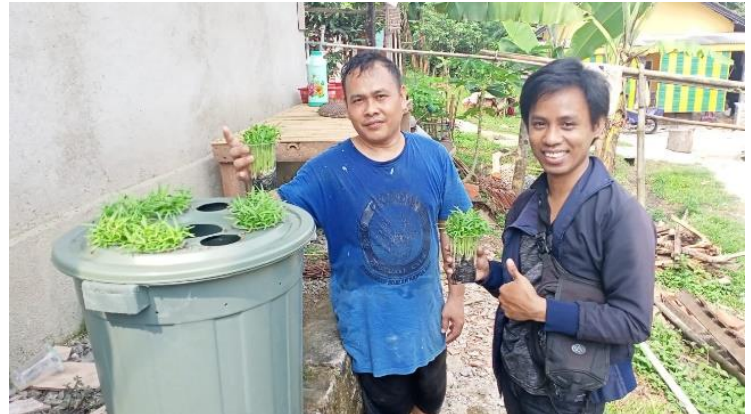

Gambar 8. Hasil evaluasi bersama salah satu warga

\section{KESIMPULAN}

Secara umum peserta penyuluhan sebanyak 30 warga Desa Kareo mendapatkan wawasan dan ilmu pengetahuan baru mengenai teknologi budidaya ikan dalam ember dan cara mengolah serta mengemasnya. Pada proses 
aplikasi/praktik, sebanyak $80 \%$ warga yang memelihara menerapkan kegiatan budidaya dengan baik. Hal itu terlihat dari jumlah mortalitas ikan yang kurang dari $70 \%$ dan kondisi kangkung yang normal. Penerapan program budidaya ikan dalam ember ini memberikan antusias yang luar biasa sebagai gerakan masyarakat dalam mendukung ketahanan pangan pada masa pandemi Covid-19.

\section{UCAPAN TERIMA KASIH}

Penulis menyampaikan banyak terima kasih kepada Lembaga Penelitian dan Pengabdian Kepada Masyarakat Universitas Sultan Ageng Tirtayasa atas dukungan pendanaan dan bantuannya melalui "Program Pengabdian Pada Masyarakat Tahun 2020". Selain itu penulis juga mengucapkan terima kasih kepada Ketua RT 11 dan 12 Desa Kareo, Kecamatan Jawilan, Kabupaten Serang, Banten.

\section{DAFTAR PUSTAKA}

Astuti, K. I., \& Fitriyanti. (2018). Uji potensi efek sedatif-hipnotik ekstrak etanol kangkung air (Ipomoea aquatic) asal Gambut Kalimantan Selatan. Borneo Journal of Pharmascientech, 02(02), 5964.

BPS. (2019). Kecamatan Jawilan Dalam Angka 2019. Badan Pusat Statistik Kabupaten Serang.

Kurniawansyah, H., Amrullah, Salahuddin, M., Muslim, \& Nurhidayati, S. (2020). Konsep kebijakan strategis dalam menangani eksternalitas ekonomi dari Covid - 19 pada masyarakat rentan di Indonesia. Indonesian Journal of Social Sciences and Humanities, 1(2), 130-139.

Nazlia, S., \& Zulfiadi. (2018). Pengaruh tanaman berbeda pada sistem akuaponik terhadap tingkat kelangsungan hidup dan pertumbuhan ikan lele (Clarias sp.). Acta Aquatica, 5(1), 14-18.

Perwitasari, D. A., Amani, T., \& Gending, T. K. (2019). Penerapan sistem akuaponik (budidaya ikan dalam ember) untuk pemenuhan gizi dalam mencegah stunting di Desa Gending Kabupaten Probolinggo. Jurnal Abdi Panca Marga, 1(1), 20-24.

Pratama, G., Kurniawan, I. D., \& Ilhamdy, A. F. (2020). Pengendalian pencemaran limbah domestik sebagai upaya rehabilitasi pesisir di Desa Malangrapat,
Kabupaten Bintan. PRIMA: Journal of Community Empowering and Services, 4(1), https://doi.org/10.20961/prima.v4i1.41228

Purnama, S. (2019). Ketersediaan dan kualitas air tanah pada akuifer tidak tertekan di Kecamatan Jawilan dan Kopo, Kabupaten Serang. Majalah Geografi Indonesia, 33(1), 16-25. https://doi.org/10.22146/mgi.38813

Purwaningsih, Y. (2008). Ketahanan pangan: situasi, permasalahan, kebijakan dan pemberdayaan masyarakat. Jurnal Ekonomi Pembangunan, 9(1), 1-27.

Riyanto, J., Lutojo, L., \& Sunarto, S. (2020). Aplikasi penggunaan konsentrat pemacu pertumbuhan untuk penggemukan sapi potong di Karanganyar. PRIMA: Journal of Community Empowering and Services, 4(1), https://doi.org/10.20961/prima.v4i1.37988

Rohmah, S. N. (2020). Adakah peluang bisnis di tengah kelesuan perekonomian akibat pandemi Coronavirus Covid-19?. Adalah, $4(1), 63-74$.

Saputri, S. A. D., \& Rachmawatie, D. (2020). Budidaya ikan dalam ember: strategi keluarga dalam rangka memperkuat ketahanan pangan di tengah pandemi Covid-19. Jurnal Ilmu Pertanian Tirtayasa, 2(1), 102-109.

Sarip, Syarifudin, A., \& Muaz, A. (2020). Dampak Covid-19 terhadap perekonomian masyarakat dan pembangunan desa. AlMustashfa: Jurnal Penelitian Hukum Ekonomi Islam, 5(1), 10-20.

Sugiarso, Riyadi, A., \& Rusmadi. (2017). Pemberdayaan masyarakat melalui pemanfaatan pekarangan (PTP) untuk konservasi dan wirausaha agribisnis di Kelurahan Kedung Pane Kota Semarang. Dimas, 17(2), 343-366.

Suryani, D., Nurdjanah, E. P., Yogatama, \& Jumadil, M. (2018). Membudayakan hidup sehat melalui gerakan masyarakat (GERMAS) di Dusun Mendang III, Jambu dan Jrakah Kecamatan Tanjungsari, Gunungkidul. Jurnal Pemberdayaan, 2(1), 65-74.

Susetya, I. E., \& Harahap, Z. A. (2018). Aplikasi Budikdamber (Budidaya Ikan Dalam Ember) untuk keterbatasan lahan budidaya di Kota Medan. Abdimas Talenta, 3(2), 416-420. 
Syamsunarno, M. B., Fatmawaty, A. A., Munandar, A., \& Anggaeni, D. (2020). Pemberdayaan masyarakat melalui teknologi akuaponik untuk kemandirian angan di Desa Banyuresmi Kabupaten Pandeglang Provinsi Banten. Abdinus, 3(2), 329-341. 